\title{
A study on the evaluation of the geoid-quasigeoid separation term over Pakistan with a solution of first and second order height terms
}

\author{
Muhammad Sadiq, Zulfiqar Ahmad, and Gulraiz Akhter \\ Department of Earth Sciences, Quaid-i-Azam University, Islamabad Post Code 45320, Pakistan \\ (Received December 27, 2007; Revised November 11, 2008; Accepted January 6, 2009; Online published August 31, 2009)
}

\begin{abstract}
An attempt has been made to evaluate the geoid-quasigeoid separation term over Pakistan by using solutions of terms involving first and second order terrain heights. The first term, involving the Bouguer anomaly, has a significant value and requires being incorporated in any case for determination of the geoid from the quasigoidal solution. The results of the study show that the second term of separation, which involves the vertical gravity anomaly gradient, is significant only in areas with very high terrain elevations and reaches a maximum value of $2-3 \mathrm{~cm}$. The integration radius of $18 \mathrm{~km}$ for the evaluation of the vertical gravity anomaly gradient was found to be adequate for the near zone contribution in the case of the vertical gravity anomaly gradient. The Earth Gravity Model EGM96 height anomaly gradient terms were evaluated to assess the magnitude of the model dependent part of the separation term. The density of the topographic masses was estimated with the linear operator of vertical gravity anomaly gradient using the complete Bouguer anomaly data with an initial arbitrary density of $2.67 \mathrm{~g} / \mathrm{cm}^{3}$ to study the effect of variable Bouguer density on the geoid-quasigeoid separation. The density estimates seem to be reasonable except in the area of very high relief in the northern parts. The effect of variable density is significant in the value of the Bouguer anomaly-dependent geoid-quasigeoid separation and needs to be incorporated for its true applicability in the geoid-quasigeoid separation determination. The geoid height $(N)$ was estimated from the geoid-quasigeoid separation term plus global part of height anomaly and terrain-dependant correction terms. The results were compared with the separation term computed from EGM96-derived gravity anomalies and terrain heights to estimate its magnitude and the possible amount of commission and omission effects.
\end{abstract}

Key words: Geoid, quasigeoid, $C_{1} \& C_{2}$ correction terms, gravity anomaly, height anomaly, vertical gravity anomaly gradient.

\section{Introduction}

Most of the modern geodetic boundary value problems provide quasigeoid as its solution. The geoid-quasigeoid separation term is then required for the determination of geoid in areas where height datum is based on the orthometric height system. It is well known that rigorous determination of the geoid requires knowledge of the mass distribution of topography above the geoid. To avoid this problem, Molodensky et al. (1962) discarded the geoid and introduced a new surface, the quasigeoid, in which the geoidal undulation is replaced by height anomaly. The determination of height anomaly involves no assumption of its density in the computation, unlike the geoidal undulation $(N)$. The geoid-quasigeoid separation term can then be used for the computation of the geoid from the quasigeoid.

The separation between the quasigeoid height $\left(\zeta_{\mathrm{p}}\right)$ and the geoid height $(N)$ is derived in two different ways. Firstly, the difference between the orthometric height and the normal height yields the separation term. Secondly, the difference of the results of two Stokes formulae for the quasigeoid and the geoid can be used to achieve the purpose

Copyright (c) The Society of Geomagnetism and Earth, Planetary and Space Sciences (SGEPSS); The Seismological Society of Japan; The Volcanological Society of Japan; The Geodetic Society of Japan; The Japanese Society for Planetary Sciences; TERRAPUB
(Heiskanen and Moritz, 1967; Sjöberg, 1995). The geoid is an equipotential surface of the Earth that corresponds to mean sea level, whereas the quasigeoid is a geometrical surface referred to as a normal height system. The geoid undulation $N$ is the separation between the ellipsoid and the geoid measured along the ellipsoidal normal. The height anomaly $\left(\zeta_{\mathrm{p}}\right)$ is the separation between the reference ellipsoid and quasigeoid along the ellipsoidal normal. There is a similar concept of orthometric heights $\left(H^{\circ}\right)$ measured along the plumb line, whereas normal heights $\left(H^{\mathrm{N}}\right)$ are measured along the ellipsoidal normal. These reference surfaces are shown in Fig. 1.

The geoidal heights can also be computed from global gravity field models, as studied by Rapp (1971, 1994a, b, 1997), who examined different procedures for geoidal height computations using spherical harmonic coefficients of the global Earth gravity models. The difference in height anomaly $\zeta_{\mathrm{p}}$ and geoidal-height $N$ and a height anomaly gradient correction term can be used to achieve this purpose. Sjöberg (1995) has proposed this as an 'indirect' method; which was further investigated by Nahavandchi (2002) using EGM96 geopotential coefficients (Lemoine et al., 1997). This indirect method for geoid modeling has also been investigated for the entire area of Pakistan using observed gravity data, a global gravity model, its elevation- 


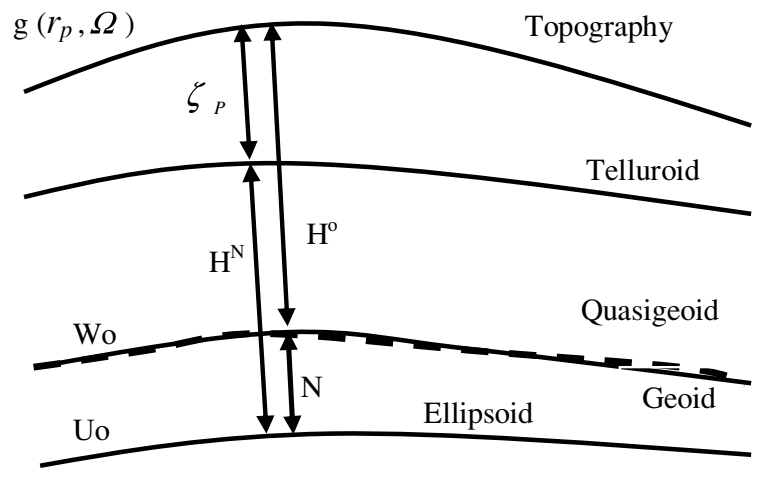

Fig. 1. The geoid undulation $(N)$, orthometric heights $\left(H^{\mathrm{o}}\right)$, height anomaly $\left(\zeta_{\mathrm{p}}\right)$, and normal heights $\left(H^{\mathrm{N}}\right)$.

dependant correction terms, and digital elevation models in addition to quantification of the difference between the geoid and height anomaly. It is a known fact that the global vertical datum, i.e. global mean sea level or geoid and local mean sea leveling data, has as an offset/bias (Lisitzin, 1974; Torge, 2001). This bias comes from the external harmonic series when applied to the geoid within the topographic masses as well as from the errors in the GPS and leveling data. Additionally, it has its source from permanent ocean dynamic topography (PODT) and mean sea level changes (Torge, 2001). Sjöberg $(1977,1994)$ pointed out this bias and Sjöberg (1994, 1995), Vanicek et al. (1995), and Nahavandchi and Sjöberg (1998) derived different terms to handle this bias, which is called the topographic correction for potential coefficients. Here an attempt has been made to quantify it through the comparison with local GPS-leveling data as the difference in the standard deviation with respect to global vertical datum.

The observed gravity anomalies, elevation data, and global geopotential model were used in this study. The model part of the gravity anomaly was computed from the EGM96 global model, and the digital elevation model data was extracted from GTOPO5 (5-arc min global topography) and Shuttle Radar Topographic Mission (SRTM30) for the whole area of Pakistan. The terrain correction was applied to the distance of $167 \mathrm{~km}\left(\sim 1.5^{\circ}\right)$ in the area and added to the Bouguer anomaly to quantify the effect of terrain on geoid-quasigeoid separation. The EGM96 global model is a reasonably good estimate of the global gravity field and height anomalies (Rapp, 1997). Other combined global models, such as the EIGEN-CG01C (Reigber et al., 2004), EIGEN-CG03C and EIGEN-GL04C (Fösrste et al., 2005, 2006) models derived from the CHAMP and GRACE satellite missions, are also good enough; however, they have comparable statistics to EGM96 in terms of observed gravity and geoid in Pakistan (Sadiq and Ahmad, 2007). The model part of the geoid-quasigeoid separation term was determined using EGM96 potential coefficients (Lemoine et al., 1997).

The height datum of Pakistan is based on the orthometric height system. Therefore, the final solution should be in the form of the geoid for surveying and other related applications. Pakistan has a variety of terrain distribution due to its vast expanse of land comprising both plain lands to mid elevation ranges and then to very high Himalayan mountain ranges. The quantification of the maximum possible value of the geoid to quasigeoid separation is essential due to the fact that most modern geodetic boundary value problems provide the quasigeoid as their final solution, with the exception of the pure Helmert condensation. The basis for this is related to the ways of handling topography in a better way in these methods, e.g., Molodensiki's method with RTM and combined RTM/Helmert schemes, among others (Omang and Forsberg, 2000). The focus of this study is mainly on the estimation of as maximum as possible complete geoid-quasigeoid separation term to be used for the determination of a geoid from a quasigeoidal solution. For this purpose, an initial study was made to investigate the geoid-quasigeoid separation term dependence on elevation by Sadiq and Ahmad (2006) as a part of geoid-quasigeoid separation $\left(N_{\mathrm{p}}-\zeta_{\mathrm{p}}\right)$ modeling study in Pakistan.

Section 2 provides a brief theoretical background for the evaluation of the geoid-quasigeoid separation term, Section 3 analyses the test results, and Section 4 presents the results with some recommendations.

\section{Brief Theoretical Background}

The geoid to quasigeoid separation term is a function of the geoid and quasigeoid in one sense and orthomeric and normal heights in the other sense. This term can be determined with adequate accuracy as a difference of the geoid and quasigeoid using terms to the second power of orthometric heights (Sjöberg, 1995) by the following relationship.

$$
N_{\mathrm{p}}-\zeta_{\mathrm{p}}=\frac{\Delta g_{\mathrm{B}}}{\bar{\gamma}} H+\frac{(H)^{2}}{2 \bar{\gamma}} \frac{\partial \Delta g^{\mathrm{F}}}{\partial H}+\text { higher order terms }
$$

where $N_{\mathrm{p}}$ and $\zeta_{\mathrm{p}}$ are the geoid and quasigeoid heights, $\Delta g_{\mathrm{B}}$ and $\Delta g^{\mathrm{F}}$ are the Bouguer and free air anomalies, $H$ is the orthometric height, and $\bar{\gamma}$ is the average theoretical gravity along the ellipsoidal normal between the surface of the geocentric reference ellipsoid and the telluroid.

Rapp (1997) pointed out that $\zeta_{\mathrm{p}}$ is dependent on the gradients of radius vector $r_{\mathrm{p}}$ and height as a function of the first order height term. The value $\zeta_{0}$ at the ellipsoidal surface needs to be corrected to obtain $\zeta$ values at $\mathrm{P}$.

$$
\zeta_{\mathrm{p}}=\zeta_{0}\left(\varphi, \lambda, r_{\mathrm{E}}\right)+\frac{\partial \zeta}{\partial r} h+\frac{\partial \zeta}{\partial \gamma} \frac{\partial \gamma}{\partial h} h
$$

where $h$ is the ellipsoidal height of point $\mathrm{P}$ and $r_{\mathrm{E}}$ is the ellipsoidal radius. We can write the final form for geoidquasigeoid separation as (Rapp, 1997; Nahavandchi, 2002)

$$
N(\varphi, \lambda)=\zeta_{0}\left(\varphi, \lambda, r_{\mathrm{E}}\right)+C_{1}(\varphi, \lambda)+C_{2}(\varphi, \lambda)
$$

where $\zeta_{0}$ is the height anomaly at the ellipsoidal surface, and $\varphi$ and $\lambda$ are the geodetic latitude and longitude, respectively

$$
C_{1}(\varphi, \lambda)=\frac{\partial \zeta}{\partial r} H+\frac{\partial \zeta}{\partial \gamma} \frac{\partial \gamma}{\partial h} H
$$

Here, orthometric height can be used instead of ellipsoidal height without any loss of accuracy (Rapp, 1997)

$$
C_{2}(\varphi, \lambda)=\frac{\Delta g_{\mathrm{B}}}{\bar{\gamma}} H+\frac{(H)^{2}}{2 \bar{\gamma}} \frac{\partial \Delta g}{\partial H} .
$$


The following convention may be adopted for naming the terms of Eqs. (4) and (5),

$$
C_{1}(\varphi, \lambda)=C_{11}(\varphi, \lambda)+C_{12}(\varphi, \lambda)
$$

and

$$
C_{2}(\varphi, \lambda)=C_{21}(\varphi, \lambda)+C_{22}(\varphi, \lambda) .
$$

The solution of Eq. (4) can be determined using the relationship for the height anomaly (Rapp, 1997) with spherical harmonic expansion to degree and order 360 as below

$$
\begin{aligned}
\zeta_{0}\left(\varphi, \lambda, r_{\mathrm{E}}\right)= & \frac{G M}{\gamma r_{\mathrm{E}}} \sum_{n=2}^{M}\left(\frac{a}{r}\right)^{n} \sum_{m=0}^{360}\left(\bar{C}_{n m} \cos m \lambda\right. \\
& \left.+\bar{S}_{n m} \sin m \lambda\right) \bar{P}_{n m}(\sin \varphi)
\end{aligned}
$$

where $\gamma$ is the normal gravity at the ellipsoid and $a$ is its semi-major axis, $\bar{C}_{n m} \bar{S}_{n m}$ are fully normalized potential coefficients of degree $n$ and order $m$, and $\bar{P}_{n m}$ is fully normalized Legendre function. The first and second term of Eq. (4) can be determined using Eq. (8) as follows.

$$
\begin{aligned}
\frac{\partial \zeta}{\partial r} H= & -\frac{G M}{\gamma r^{2}} H \sum_{n=2}^{M}(n+1) \times\left(\frac{a}{r}\right)^{n} \\
& \cdot \sum_{m=0}^{360}\left(\bar{C}_{n m} \cos m \lambda+\bar{S}_{n m} \sin m \lambda\right) \bar{P}_{n m}(\sin \varphi) \\
\frac{\partial \zeta}{\partial \gamma} \frac{\partial \gamma}{\partial h} H= & 0.3086 * H_{\mathrm{o}} \frac{G M}{\gamma^{2} r} \times \sum_{n=2}^{M}\left(\frac{a}{r}\right)^{n} \\
& \cdot \sum_{m=0}^{360}\left(\bar{C}_{n m} \cos m \lambda+\bar{S}_{n m} \sin m \lambda\right) \bar{P}_{n m}(\sin \varphi)
\end{aligned}
$$

The two parts of the $C_{1}$ term $\left(C_{11}\right.$ and $\left.C_{12}\right)$ were determined by Eqs. (9) and (10) using height data and gravity-mass constant $G M$ with the definition of $W_{\mathrm{o}}$ (Bursa, 1995) in a non-tidal system. Here, we have used $3.986004418 \mathrm{E}+10^{14} \mathrm{~m}^{3} \mathrm{~s}^{-2}$ for $G M$ in order to make consistent calculations with respect to the tidal system used.

The first term of Eq. (5) is simple to compute. The second term, the height gradient of free air anomaly, requires special solution techniques and is given by Heiskanen and Moritz (1967) as

$$
\left(\frac{\partial \Delta g^{\mathrm{F}}}{\partial H}\right)_{\mathrm{p}}=\frac{R^{2}}{2 \pi} \iint_{\sigma} \frac{\Delta g^{\mathrm{F}}-\Delta g_{\mathrm{p}}^{\mathrm{F}}}{l_{\mathrm{o}}^{3}} d \sigma-\frac{2}{R} \Delta g_{\mathrm{p}}^{\mathrm{F}}
$$

where $l_{\mathrm{o}}$ is the spatial distance between the computation point $\mathrm{P}$ and the running point, $R$ is the average earth radius, and $\sigma$ is the unit sphere. The planar solution of Eq. (2), as given by Heiskanen and Moritz (1967), can be written as

$$
\frac{\partial \Delta g^{\mathrm{F}}}{\partial H}=\frac{s_{0}}{4}\left(g_{x x}+g_{y y}\right)
$$

where $s_{0}$ is the constant linear distance (here it is the grid interval of the gridded data), and $g_{x x}$ and $g_{y y}$ are the second order horizontal derivatives of the free air gravity anomaly.
The horizontal second order derivatives were calculated from the gridded free air anomaly data at $5^{\prime}$ arc minute grid intervals.

The approximation of the vertical gravity anomaly gradient with Eq. (12) is not very accurate, but it can be improved with numerical integration for greater integration radii. For this purpose, the solution of Eq. (11) was determined numerically using Newton-Cotes formulae after solving the singular integral in the planar approximation. The planar/flat Earth approximation of the vertical gravity anomaly gradient is expressed as (Heiskanen and Moritz, 1967; Bian and Dong, 1991; Bian, 1997).

$$
\frac{\partial \Delta g}{\partial H}=\frac{1}{2 \pi} \iint \frac{\Delta g(x, y)-\Delta g_{0}}{r^{3}} d x d y
$$

where $\Delta g_{0}$ is the free air gravity anomaly at the computation point and $r=\sqrt{x^{2}+y^{2}}$, where $x$ and $y$ are tangent planar coordinates of the moving point. The solution for the inner most area, $-2 a<x<2 a,-2 a<y<2 a$, was implemented on the gridded data with a planar approximation with a grid interval ' $a$ '. The final solution for the vertical gravity anomaly gradient comes out to be

$$
\begin{aligned}
& \frac{\partial \Delta g}{\partial H}=\frac{1}{135 a \pi}\{36 \ln (1+\sqrt{2})+128\} \\
& \cdot(\Delta g(-a, 0)+\Delta g(a, 0)+\Delta g(0,-a)+\Delta g(0, a) \\
& -4 \Delta g(0,0)) \\
& +\frac{49}{8100 a \pi \sqrt{2}} \\
& \cdot(\Delta g(-2 a, 2 a)+\Delta g(2 a,-2 a)+\Delta g(2 a, 2 a) \\
& +\Delta g(-2 a,-2 a)-4 \Delta g(0,0)) \\
& +\frac{84}{8100 a \pi} \\
& \cdot(\Delta g(-2 a, 0)+\Delta g(2 a, 0)+\Delta g(0,2 a) \\
& +\Delta g(0,-2 a)-4 \Delta g(0,0)) \\
& +\frac{448}{10125 a \pi \sqrt{5}} \\
& \cdot(\Delta g(-2 a, a)+\Delta g(2 a,-a)+\Delta g(a,-2 a) \\
& +\Delta g(-a, 2 a)+\Delta g(-2 a,-a)+\Delta g(2 a, a) \\
& +\Delta g(-a,-2 a)+\Delta g(a, 2 a)-8 \Delta g(0,0)) \\
& +\frac{56}{6075 a^{3} \pi \sqrt{2}} \\
& \cdot(\Delta g(-a, a)+\Delta g(a,-a)+\Delta g(-a,-a) \\
& +\Delta g(a, a)-8 \Delta g(0,0))
\end{aligned}
$$

The average integration radius corresponding to the Newton-Cotes formula for $n=4$ with a grid interval of 5 arc min was used in this study. Additionally, the even orders of the Newton-Cotes integration yield exact results. This is due to the reason that the fourth order was found to be enough for estimating of the vertical gravity anomaly gradient through Eq. (14) in the innermost zone for medium elevation ranges (Sadiq et al., 2008). In addition to this, it is also known that the vertical gravity anomaly dependent $C_{22}$, i.e., second term of Eq. (1) is of much less magnitude (only $\sim 2-3 \%$ ) in comparison with the $C_{21}$ correction term. 
Table 1. Statistics of the input parameters for the computation of the geoid-quasigeoid separation term.

\begin{tabular}{lcccc}
\hline Parameter & Min & Max & Mean & Std. dev. \\
\hline Altitude (m) & -3836.2 & 6143.8 & 374.45 & 1767.74 \\
Bouguer Anomaly (mgal) & -559.85 & 132.2 & -91.69 & 114.03 \\
Free air Anomaly (mgal) & -290.97 & 256.25 & -39.09 & 76.512 \\
Terrain correction (mgal) & -64.264 & 229.13 & 16.92 & 27.04 \\
\hline
\end{tabular}

\section{Data Processing Strategy and Analysis of Re- sults}

The gravity data for the numerical investigation was taken from the GETECH database (GETECH, 1995) for Bouguer gravity anomalies over Pakistan with a $5^{\prime}$ grid interval. The digital elevation model of GTOPO5 and SRTM30 were also available for the computation terrainrelated gravity field parameters. The topographic heights vary from 3836.2 to $6143.8 \mathrm{~m}$ within the study area. Since GTOPO5 elevation data were used for the evaluation of Bouguer anomaly, the free air anomaly was computed by the back transformation of the procedure implemented for the determination of the Bouguer anomaly. The Bouguer gravity anomaly varies from $-559.85 \mathrm{mgal}$ to $132.2 \mathrm{mgal}$ with a constant topographic density of $2.67 \mathrm{~g} / \mathrm{cm}^{3}$. The free air anomaly ranges from -290.97 to $256.25 \mathrm{mgal}$. The terrain-corrected Bouguer anomaly is preferred for the estimation of the $C_{21}$ correction term. To this end, the terrain correction was estimated via prism integration using the GRAVSOFT (2005) program and was computed by using a 30-arc second resolution SRTM30 grid along with intermediate (5-arc min grid) and reference grid (30-arc min grid). It varies from -64.264 to $229.133 \mathrm{mgal}$ in the study area. The theoretical normal gravity (i.e., $\gamma$ ) at the ellipsoidal surface was computed using Somigliana's formula. The statistics of input gravity field parameters is shown in Table 1.

For better management and data manipulation requirements, the whole area of Pakistan was divided into two parts, namely PKGRD1 and PKGRD2, for the estimation of the $C_{22}$ term using free air gravity anomalies. The data around the Pakistan were filled with EGM96 free air anomaly data to make the above two grids as regular and rectangular as possible and therefore useful for computating first and second order horizontal derivatives. These derivatives were used in Eq. (14) to compute the vertical gravity anomaly gradient, which was further used in Eq. (5) to compute the $C_{22}$ part of the geoid-quasigeoid separation $C_{2}$ term.

The global geopotential model-dependent $C_{1}$ term (Eqs. (9) and (10)) was computed by employing the global gravity model and digital elevation data (GTOPO5 and SRTM30). To this end, the EGM96 model with its geopotential coefficients was used for the maximum degree of expansion, i.e., degree and order of 360 . The ground gravity data-dependent $C_{2}$ term was computed while using the digital elevation model and ground gravity free air and Bouguer gravity anomalies. The computation of $C_{21}$ and $C_{22}$ was performed using actual data of the GETECH grid available within the GETECH database along with terrain cor- rections.

\subsection{Development of topographic density model}

The $C_{21}$ part of the separation term, which is dependent on the Bouguer anomaly, has a built-in supposition of constant density of $2.67 \mathrm{~g} / \mathrm{cm}^{3}$. The use of constant density introduces errors into the reduced gravity anomalies (e.g., simple Bouguer anomaly and its terrain-corrected version) and, consequently, in the geoid-quasigeoid separation and geoid itself.

Several studies have been conducted using laterally varying topographic density models in gravimetric geoid computations (e.g., Martinec et al., 1995; Kuhtreiber, 1998; Pagiatakis and Armenakis, 1999; Tziavos and Featherstone, 2000; Huang et al., 2001; Hunegnaw, 2001). Different approaches can be used for the development of a density model in a particular area. The first, but rather difficult, approach is the direct measurement and collection of samples. This method has limitations due to inaccessibility and may not be representative. The other well-known geophysical method is the use of the density profile approach (Nettleton, 1971). An extension of this method is density estimation using a linear least squares regression for the distributed over an area (Helmut, 1965). One important geophysical technique is the well-logs investigation method. From a practical point of view, it is very expensive and is usually used only for special exploration projects (e.g., oil exploration, etc.). The information derived from geological maps can be utilized for establishing topographic density models. Various researchers around the world (see Martinec, 1993; Pagiatakis and Armenakis, 1999; Kuhn, 2000a, b; Tziavos and Featherstone, 2000; Huang et al., 2001; Kiamehr, 2006) have successfully used geological maps to generate density models. A 3-D digital density model is usually needed to give a better description of the topographic masses, but the development of such a model can be very difficult or almost impossible. Nevertheless, an approximate density model would improve the gravity reduction in a precise geoid determination rather than assuming an unrealistic constant density model (Kiamehr, 2006). In addition to this, true seismic velocities of the crustal layer can be very well employed for estimating crustal rock density (Nafe and Drake, 1963). Another workable approach may be Fractal dimension estimation from Bouguer anomaly data for density determination (Thorarinsson and Magnusson, 1990).

In the present study, an attempt was also made to evaluate and estimate the effect of the true average density on geoid-quasigeoid separation in the maximum part of the study area. To this end, the generalized procedure of linear regression (Helmut, 1965) was implemented for the evaluation of Bouguer density using the Bouguer anomaly and terrain correction-dependant term (Eq. (16)) in the following form.

$$
d=d_{\mathrm{o}}-\frac{\left[\frac{\partial^{2} B_{\mathrm{o}}}{\partial Z^{2}} \frac{\partial E}{\partial Z} E\right]}{\left[\frac{\partial^{2} E}{\partial Z^{2}} \frac{\partial E}{\partial Z} E\right]}
$$

where $B_{\mathrm{o}}$ is the arbitrary Bouguer anomaly using density ' $d_{0}$ ' of $2.67 \mathrm{~g} / \mathrm{cm}^{3}$ and ' $Z$ ' is the vertical height for the 
Table 2. The topographic densities determined using the generalized Nettleton Procedure.

\begin{tabular}{lllc}
\hline \multicolumn{3}{c}{ Grid description } & Density $\left(\mathrm{g} / \mathrm{cm}^{3}\right)$ \\
\hline Grid-1 & $22.0^{\circ}-25.7^{\circ} \mathrm{N}$ & $60.0^{\circ}-64.0^{\circ} \mathrm{E}$ & 2.643 \\
Grid-2 & $22.0^{\circ}-25.7^{\circ} \mathrm{N}$ & $64.0833^{\circ}-69^{\circ} \mathrm{E}$ & 2.728 \\
Grid-3 & $24.0^{\circ}-27.667^{\circ} \mathrm{N}$ & $69.0833^{\circ}-71.2^{\circ} \mathrm{E}$ & 2.632 \\
Grid-4 & $25.8^{\circ}-30.25^{\circ} \mathrm{N}$ & $61.0^{\circ}-65.667^{\circ} \mathrm{E}$ & 2.661 \\
Grid-5 & $27.75^{\circ}-30.25^{\circ} \mathrm{N}$ & $65.75^{\circ}-71.25^{\circ} \mathrm{E}$ & 2.634 \\
Grid-6 & $30.0^{\circ}-32.0^{\circ} \mathrm{N}$ & $66.0^{\circ}-69.0^{\circ} \mathrm{E}$ & 2.654 \\
Grid-7 & $30.333^{\circ}-32.25^{\circ} \mathrm{N}$ & $69.0^{\circ}-71.0^{\circ} \mathrm{E}$ & 2.807 \\
Grid-8 & $27.833^{\circ}-34.2^{\circ} \mathrm{N}$ & $71.33^{\circ}-75.5^{\circ} \mathrm{E}$ & 2.625 \\
Grid-9 & $32.333^{\circ}-34.5^{\circ} \mathrm{N}$ & $69.0^{\circ}-75.5^{\circ} \mathrm{E}$ & 2.848 \\
Grid-10 & $34.3^{\circ}-37.0^{\circ} \mathrm{N}$ & $70.5^{\circ}-77.0^{\circ} \mathrm{E}$ & 2.929 \\
\hline
\end{tabular}

computation of the vertical gradient of the different terms mentioned in Eq. (15). The term ' $E$ ' is defined by

$$
E=T-0.04193 * H^{\mathrm{o}}
$$

where ' $T$ ' is terrain correction and ' $H^{\mathrm{o}}$ ' is orthometric height. For estimation of the true average density ' $d$ ', linear operators of first and second vertical derivative of the gravity anomaly were applied on the gridded data. The second term of Eq. (15) was determined for true average density ' $d$ ' for each grid, as mentioned in Table 2.

The study area was therefore divided into different grids with suitable dimensions (total of ten sub-grids for the Pakistan area) for data handling in the planar approximation and more representative density calculations. The computed average density appears to fall towards the higher side for grids 7, 9, and 10, which occurs due to the high relief and steep slopes in the northern parts. This originates from the inherent characteristics of the method resulting from the distribution of terrain and gradient of gravity anomalies.

\subsection{Analysis of results}

The procedure of computation of geoid to quasigeoid separation term has been implemented and quantified for the maximum possible area of Pakistan based on observed gravity and model datasets. The work done by Rapp (1997) and Nahavandchi (2002), with minor modifications, has been adopted in a study area which has a very high and rugged terrain. In addition to this, estimation of Bouguer density was made within Pakistan to better evaluate its effect on density-dependant geoid-quasigeoid separation, i.e., $C_{21}$.

3.2.1 The estimation of the $C_{2}$ term $\left(C_{21}\right.$ plus $\left.C_{22}\right)$ The planar approximation was applied for the solution of the singular integral of the vertical gravity anomaly gradient for the estimation of the $C_{22}$ term. The complete geoid to quasigeoid separation term as the sum of $C_{1}$ and $C_{2}$ in Eq. (3) was computed from Eqs. (4) and (5) after the individual terms had been determined using Eqs. (8), (9), (10), and (14). The global part of correction $C_{1}$ was computed from the EGM96 global gravity model.

The terrain-corrected Bouguer anomaly and topographic height were used for the calculation of the $C_{21}$ term. The variation of this term is -3.2637 to $0.0096 \mathrm{~m}$ with a standard deviation of $0.4929 \mathrm{~m}$ while using a constant density of $2.67 \mathrm{~g} / \mathrm{cm}^{3}$. This $C_{21}$ term is found to be maximum contributor towards the total effect of the geoid-quasigeoid sep-
Table 3. The statistics of different parts of the complete geoid-quasigeoid separation term $\left(C_{21}\right.$ with constant density of $\left.2.67 \mathrm{~g} / \mathrm{cm}^{3}\right)$.

\begin{tabular}{cccrc}
\hline $\begin{array}{c}\text { Statistical } \\
\text { parameter }\end{array}$ & Min. & Max. & Mean & $\begin{array}{c}\text { Standard } \\
\text { deviation }\end{array}$ \\
\hline$C_{21}(\mathrm{~m})$ & -3.2637 & 0.0096 & -0.206 & 0.4929 \\
$C_{22}(\mathrm{~m})$ & -0.0237 & 0.0279 & 0.000 & 0.0019 \\
$C_{21}+C_{22}(\mathrm{~m})$ & -3.2605 & 0.0096 & -0.204 & 0.4898 \\
$C_{11}(\mathrm{~m})$ & -0.976 & 0.3480 & -0.021 & 0.0837 \\
$C_{12}(\mathrm{~m})$ & -0.0690 & 0.0000 & -0.007 & 0.0106 \\
$C_{11}+C_{12}(\mathrm{~m})$ & -1.0150 & 0.2930 & -0.029 & 0.0900 \\
$C_{1}+C_{2}(\mathrm{~m})$ & -4.0245 & 0.0450 & -0.234 & 0.5501 \\
\hline
\end{tabular}

Table 4. The statistics of different parts of the complete geoid to quasigeoid separation term $\left(C_{21}\right.$ computed with variable density from Table 2).

\begin{tabular}{ccccc}
\hline $\begin{array}{c}\text { Statistical } \\
\text { parameter }\end{array}$ & Min. & Max. & Mean & $\begin{array}{c}\text { Standard } \\
\text { deviation }\end{array}$ \\
\hline$C_{21}(\mathrm{~m})$ & -3.580 & 0.0096 & -0.220 & 0.5375 \\
$C_{22}(\mathrm{~m})$ & -0.0237 & 0.0279 & 0.000 & 0.0019 \\
$C_{21}+C_{22}(\mathrm{~m})$ & -3.577 & 0.0096 & -0.220 & 0.5374 \\
$C_{11}(\mathrm{~m})$ & -0.976 & 0.3480 & -0.021 & 0.0837 \\
$C_{12}(\mathrm{~m})$ & -0.0690 & 0.0000 & -0.0076 & 0.0106 \\
$C_{11}+C_{12}(\mathrm{~m})$ & -1.0150 & 0.2930 & -0.0291 & 0.0900 \\
$C_{1}+C_{2}(\mathrm{~m})$ & -4.329 & 0.0391 & -0.2495 & 0.597 \\
\hline
\end{tabular}

aration term due to the Bouguer plate effect, as shown in Fig. 2.

The variable density for different grids suitably selected was also used for grids 1-10 (Table 2). The estimates of densities for grids 7, 9, and 10 seem to be relatively higher. The density values for the remaining seven grids are as expected and seem to be realistic estimates. The estimation of the $C_{21}$ term from the Bouguer anomaly was made with constant as well as variable density data. The effect of variable densities appears to be considerable (Tables 3 and 4) and needs to be incorporated for better modeling of this term. The mean and standard deviation differences of the $C_{21}$ term for the two cases are 13.9 and $44.6 \mathrm{~mm}$. This, however, requires that the density modeling be verified by some other independent method, such as computed from Fractal dimension estimation of Bouguer densities (Thorarinsson and Magnusson, 1990) and/or seismic velocities of topographic masses (Nafe and Drake, 1963), among others. The results of variable and constant density are shown in Tables 3 and 4 . The second part of the $C_{2}$ term, i.e., $C_{22}$, was computed using free air gravity anomaly data on the grid of $5^{\prime} \times 5^{\prime}$. The whole study area was divided into two parts, keeping in mind the distribution of data and extensions. The computed first and second horizontal derivatives were used in Eq. (14) to compute the vertical gravity anomaly gradient, which was then used in Eq. (5) to compute this second part of $C_{2}$ term.

During the computation of the vertical gravity anomaly gradient, it was observed that Newton-Cotes formula for $n=4$ seems to be adequate for practical purposes for the evaluation of the $C_{22}$ term. The variation in the $C_{22}$ term over the whole study area ranges from -23.7 to $27.9 \mathrm{~mm}$ and is only approximately $1.5 \%$ of the Bouguer anomaly- 
Table 5. The statistics of different parts of complete geoid to quasigeoid separation term and EGM96 height anomaly $\left(C_{21}\right.$ determined using the EGM96 correction coefficients set).

\begin{tabular}{ccccc}
\hline Statistical parameter & Min. & Max. & Mean & Std. dev. \\
\hline EGM96 height anomaly (m) & -54.08 & -17.19 & -39.263 & 7.92 \\
$C_{21}$ (EGM96 Corr. Coeff.) $(\mathrm{m})$ & -3.42 & 0.05 & -0.220 & 0.557 \\
$C_{22}(\mathrm{~m})$ & -0.024 & 0.0279 & 0.0000 & 0.0019 \\
$C_{21}+C_{22}(\mathrm{~m})$ & -3.419 & 0.0499 & -0.220 & 0.5568 \\
$C_{11}(\mathrm{~m})$ & -0.976 & 0.3480 & -0.021 & 0.0837 \\
$C_{12}(\mathrm{~m})$ & -0.069 & 0.0000 & -0.0076 & 0.0106 \\
$C_{11}+C_{12}(\mathrm{~m})$ & -1.0150 & 0.2930 & -0.0291 & 0.0900 \\
$C_{1}+C_{2}(\mathrm{~m})$ & -4.0647 & 0.167 & -0.249 & 0.6189 \\
\hline
\end{tabular}

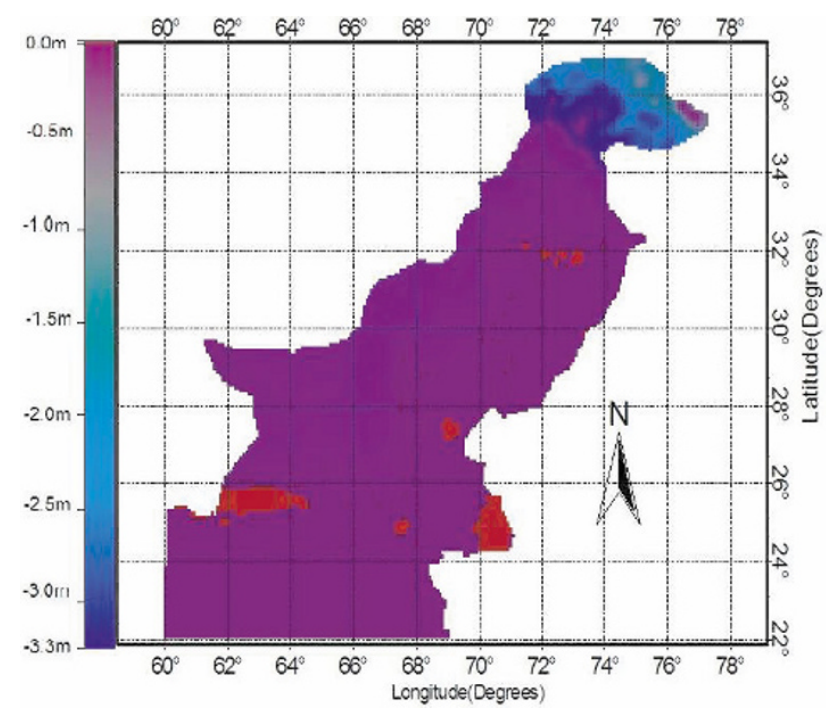

Fig. 2. The image plot of the $C_{21}$ part of the geoid-quasigeoid separation.

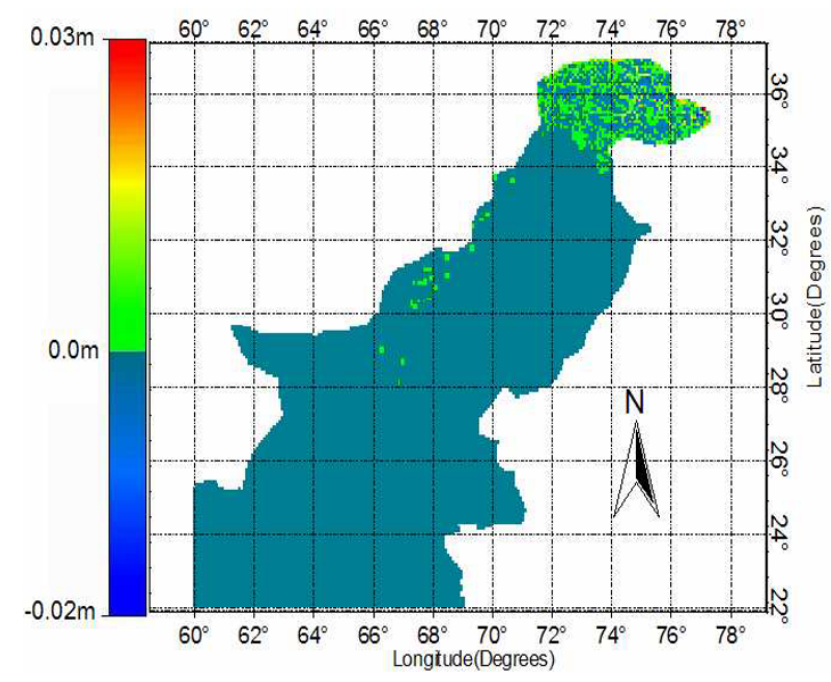

Fig. 3. The image plot of the $C_{22}$ part of geoid-quasigeoid separation.

dependant term $C_{21}$. This shows that the $C_{22}$ part is insignificant in the complete $C_{2}$ term and that the overall statistics of the $C_{2}$ term does not change very much because it has been statistically hidden by the major part of $C_{21}$, as has been shown in Fig. 3.
3.2.2 Estimation of the $\boldsymbol{C}_{\boldsymbol{1}}$ term $\left(\boldsymbol{C}_{\mathbf{1 1}}\right.$ plus $\left.\boldsymbol{C}_{\mathbf{1 2}}\right)$ The $C_{1}$ term was computed from the global geopotential coefficients of EGM96 from the expansion up to order and $360^{\circ}$ with height anomaly gradient terms using Eqs. (9) and (10) and implemented with some modifications in the software F477S.FOR (Rapp, 1982). After this implementation, the program calculates these $C_{11}$ and $C_{12}$ terms at the surface of earth. The gradient term $C_{1}$ for the geoid-quasigeoid separation requires the data of topographic height and the potential coefficient of the recent earth gravity model.

The total $C_{1}$ term (sum of $C_{11}$ and $C_{12}$ ) varies from -1.032 to $0.293 \mathrm{~m}$ in the whole study area. The overall effect on the total geoid-quasigeoid separation term is found to be additive in general, as it is evident from the statistics given in Tables 4 and 5 and maps shown in Figs. 4, 5, and 6. The contour pattern of the $C_{1}$ term shows a similar trend of increase in magnitude from low land areas towards the high mountains, as it is observable in the $C_{21}$ and $C_{22}$ terms.

The model part of the geoid-quasigeoid separation term (Fig. 7) was computed to assess its magnitude in comparison with one computed in the scheme above. This separation term was computed using EGM96 model (Lemoine et al., 1997) with the geopotential coefficients and geoidquasigeoid correction coefficients determined by Rapp (1997) from the values of the $C_{1}$ and $C_{2}$ terms using global $30^{\prime} \times 30^{\prime}$ gravity anomaly data; for details, see the paper from Rapp (1997). The harmonic expansion for the correction term was made to $360^{\circ}$ so that the corresponding cell size is $30^{\prime} \times 30^{\prime}$ to match the resolution with EGM96. With this information now available, the $C_{1}$ and $C_{2}$ terms can be evaluated on a global grid. This correction term refers to the WGS84 ellipsoid. The computation of $C_{1}$ and $C_{2}$ was made using program F477.FOR (Rapp, 1982). These data however, are missing the $C_{12}$ and $C_{22}$ terms. It is observable from our results that it does not differ much from the total $C_{2}$ term obtained from observed gravity data except the height anomaly gradient term $C_{12}$ and $C_{22}$ obtained from the free air vertical gravity anomaly gradient. This result shows that the EGM96 earth gravity model-based $C_{21}$ term corresponds nearly to GTECH data in Pakistan area computed with variable densities. The comparison of Tables 3 and 5 clearly shows that EGM96-dependant geoidquasigeoid separation is closer to variable density based results from observed data rather than for constant density. Statistics for the geoid to quasigeoid separation term and model height anomaly is given in Table 5 for comparison.

The method described above can be used for the deter- 


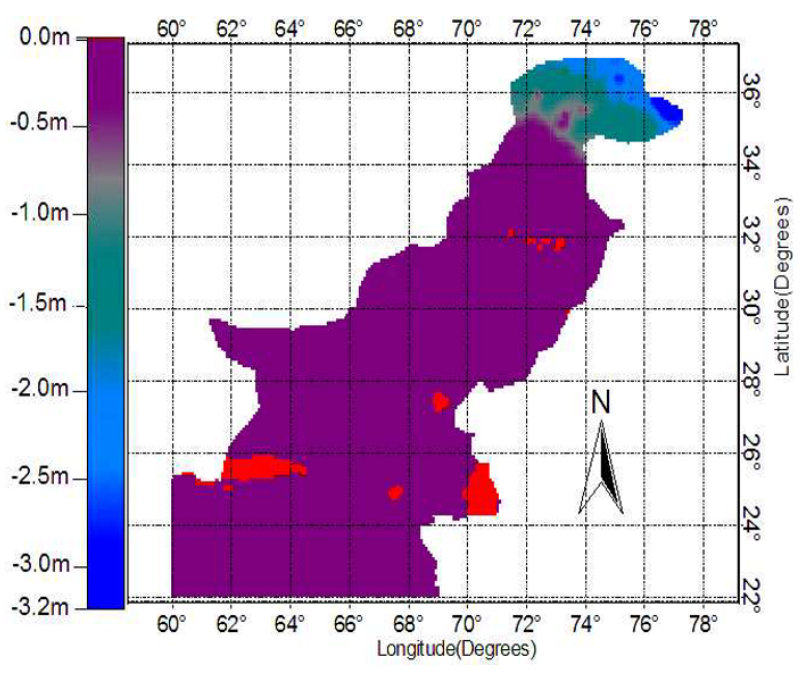

Fig. 4. The image plot of the $C_{2}$ part of the geoid-quasigeoid separation.

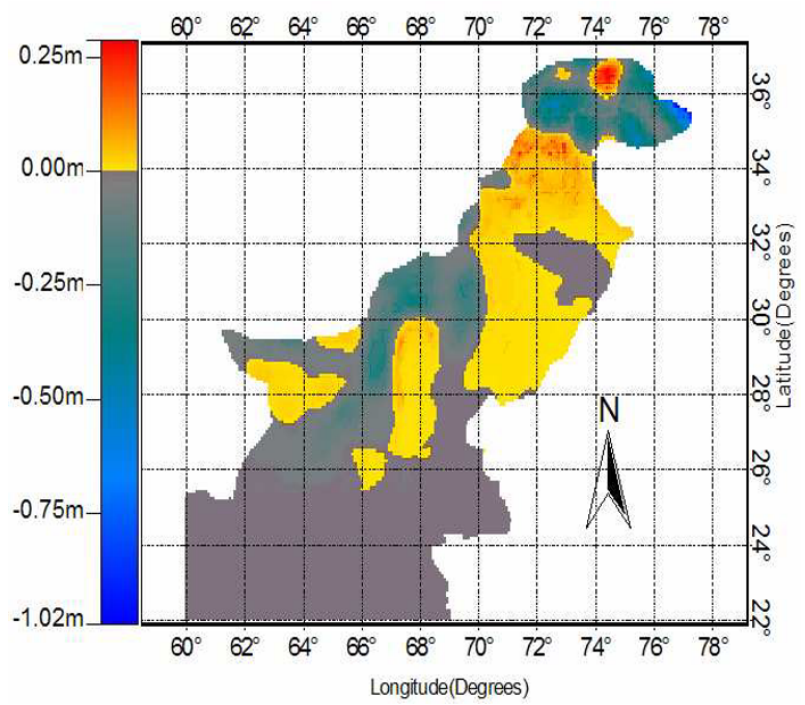

Fig. 5. The image plot of the $C_{1}$ part of the geoid-quasigeoid separation.

mination of geodal height $(N)$ from the height anomaly $\zeta_{\mathrm{p}}$ and additional $C_{1}$ and $C_{2}$ terms dependent on $H$ and $H^{2}$ as mentioned in Eqs. (1), (2), and (3) in Section 2. This scheme has been proposed to be indirect geoid determination method based on gravimetric data (Sjöberg, 1995; Nahavandchi, 2002; section 3). For comparison purposes, we computed the geoid using this method and compared it with GPS-leveling geoid data at 35 selected points. The height anomaly was computed using Eq. (8) at the ellipsoidal surface by employing the EGM96 potential coefficients up to order and degree 360 at the locations of the GPS-leveling data points. The $C_{1}$ and $C_{2}$ terms were computed at the same locations using the results of Eqs. (4) and (5), respectively.

The GPS-leveling geoidal heights $(N)$ were computed using the difference between ellipsoidal heights $(h)$, measured with the differential global positioning system (DGPS), and orthometric heights $(H)$, obtained from pre-

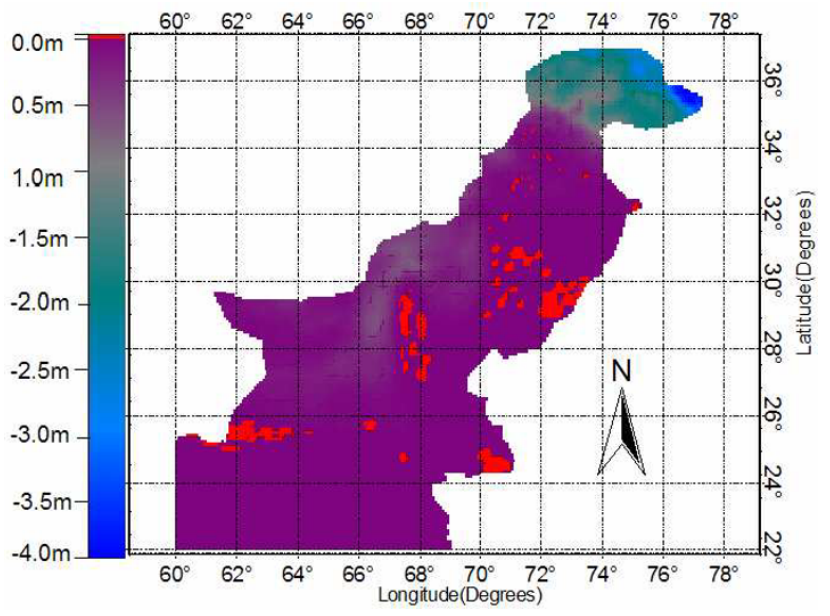

Fig. 6. The image plot of the sum of $C_{1}$ and $C_{2}$ of geoid-quasigeoid separation.

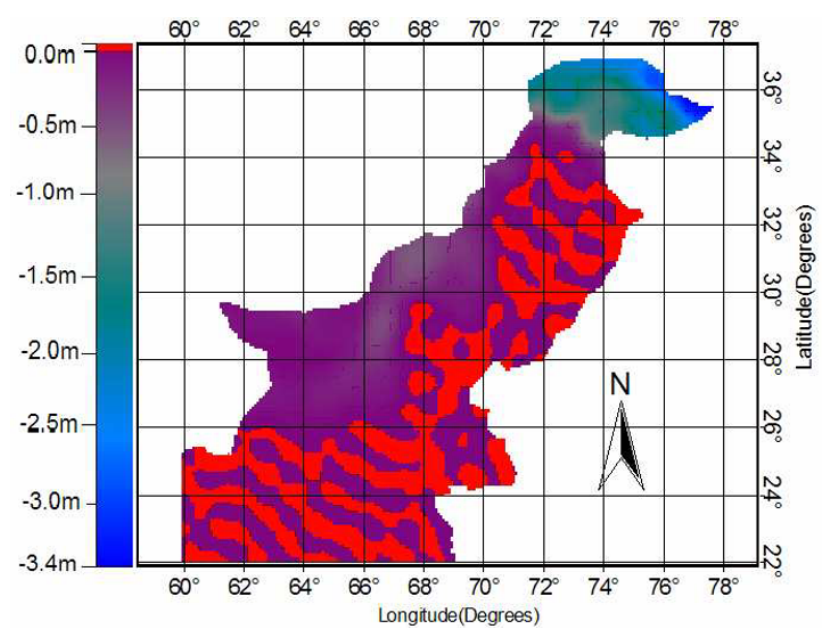

Fig. 7. The image plot of geoid-quasigeoid $C$ term separation using EGM96 data.

cise leveling data with simple relation

$$
N=h-H \text {. }
$$

The GPS ellipsoidal height data were collected and processed by the Survey of Pakistan and was connected to the high precision first order leveling network already established (Noor et al., 1997). The GPS bench marks were comprised ten GPS control points, and the other 25 points belonged to the Pakistani first order geodetic network. The processed DGPS 3-D coordinate data have a maximum error of $10 \mathrm{~cm}$ in the ITRF94 reference frame (Noor et al., 1997). The high precision leveling data has a maximum error of $2 \mathrm{~cm}$ as absolute. The statistics of differences between the computed gravimetric and GPS-Leveling geoidal heights at 35 stations are shown in Table 6.

An important result evident from Table 6 is that the standard deviation of the difference between the global gravimetric datum and local GPS-leveling datum is about $0.7 \mathrm{~m}$ - a bias value of the local vertical datum with global datum (Andersen et al., 2005) in the Karachi area of the Indian Ocean (personal communication with Ole B. An- 
Table 6. Statistics of differences between gravimetric and GPS-leveling derived geoid heights for 35 GPS-leveling stations.

\begin{tabular}{|c|c|c|c|c|}
\hline Model type & Min. & Max. & Mean & Std. dev \\
\hline Difference b/w GPS Leveling \& gravimetric geoids (m) & -1.741 & 1.477 & -0.318 & 0.773 \\
\hline Difference b/w GPS Leveling \& EGM96 geoids with EGM96 correction term added (m) & -1.235 & 2.002 & 0.206 & 0.775 \\
\hline
\end{tabular}

derson, Neil's Bohr Institute). However, this height bias value can not be representative of the total datum height offset due to insufficient GPS-leveling data (only 35 numbers) and not well-distributed data in the Pakistan area in addition to the other inherent errors of geodetic measurements. Since both gravimetric as well as EGM96-derived results are representative of the global datum, the difference is almost the same in terms of local GPS-leveling data. A maximum difference of $-1.741 \mathrm{~m}$ has been computed with respect to the gravimetric and GPS-leveling geoid. The reason behind this difference might be associated with errors in the GPS-leveling data, heights derived from GTOPO5, observed gravity data, and errors in the modeling of density in the determination of the geoid-quasigeoid separation term, in addition to the constant height offset between local and global vertical datums in the Pakistan area. In addition to this, the geoidal height determined through the height anomaly has shown good agreement with the GPS-leveling data, though some high-frequency information, i.e., terrain effects etc, is not present in this approach (Nahavandchi, 2002). This method can give better results by increasing the accuracy of potential coefficient models through the addition of high-frequency information from land gravity and terrain data and increasing the maximum degree of expansion in future global geopotential models.

\section{Conclusion and Recommendations}

This study focuses on the computation and assessment of the complete geoid to quasigeoid separation term for the selection of the onward geoid determination method. Pakistan has an orthometric height system, therefore this correction term will facilitate the determination of the geoid in Pakistan more precisely, if the height anomaly is calculated from observed gravity data using the solution of the geodetic boundary value problem based on Molodensiky's approach. The geoidal heights determined through height anomaly and terrain-dependant correction terms has demonstrated relatively good agreement to GPS-leveling data in comparison to those computed from the EGM96 model and its geoid-quasigeoid correction coefficients set. The results of our comparison confirm the difference of global vertical datum and local GPS-leveling datum to be of the order of $0.7 \mathrm{~m}$ in the sense of height bias; however, this comparison is not complete in the sense that GPSleveling data were not sufficient and well distributed. This comparison requires more GPS-leveling data in the whole area of Pakistan for better confidence on the derived results. The results might also be improved by calculating the height anomaly component from observed gravity data. Additional bench mark data are required to obtain the better comparison results. Some additional work is required for the calculation of this separation term using more redundant and reliable density estimates by some other work- able independent method, such as the Fractal dimension of the Bouguer anomaly or from seismic velocities data to estimate the Bouguer density evaluation.

Acknowledgments. Higher Education Commission of Pakistan is highly acknowledged for sponsoring this study under the indigenous Ph.D. program at the Department of Earth Sciences Quaid-i-Azam University (QAU) Islamabad, Pakistan. The Directorate General of Petroleum Concessions (DGPC), Ministry of Petroleum and Natural Resources Islamabad, GTECH, University of Leeds, UK and Survey of Pakistan are also acknowledged for providing the gravity, elevation, and GPS-leveling data of the study area to the Department of Earth Sciences, QAU, Islamabad for this research. The authors also appreciate the valuable suggestions and comments from the associate editor and two anonymous reviewers.

\section{References}

Andersen, O. B., L. Anne, Vest, and P. Knudsen, The KMS04 MultiMission mean Sea Surface, Proceedings of the Workshop GOCINA: Improving modeling of ocean transport and climate prediction in the North Atlantic region using GOCE gravimetry, April 13-15, 2005, Novotel, Luxembourg, 2005.

Bian, S., Some cubature formulas for singular integrals in geodesy, $J$. Geod., 71, 443-453, 1997.

Bian, S. and X. Dong, On the singular integration in physical geodesy, Manuscr. Geod., 16, 283-287, 1991.

Bursa, M., Report of Special Commission SC3, Fundamental constants, International Association of Geodesy, Paris, 1995.

Fösrste, C., F. Flechtner, R. Schmidt, U. Meyer, R. Stubenvoll, F. Barthelmes, R. König, K. H. Neumayer, M. Rothacher, Ch. Reigber, R. Biancale, S. Bruinsma, J.-M. Lemoine, and J. C. Raimondo, A new high resolution global gravity field model derived from combination of GRACE and CHAMP mission and altimetry/gravimetry surface gravity data, Poster presented at EGU General Assem. 2005, Vienna, Austria, 24-29, April, 2005, 2005.

Fösrste, C., F. Flechtner, R. Schmidt, R. König, U. Meyer, R. Stubenvoll, M. Rothacher, F. Barthelmes, H. Neumayer, R. Biancale, S. Bruinsma, J.-M. Lemoine, and S. Loyer, A mean global gravity field model from the combination of satellite mission and altimetry/gravimetry surface data-EIGEN-G104C, Geophys. Res. Abst., 8, 03462, 2006.

GETECH, GETECH report on South East Asia Gravity project (SEAGP), GETECH Group plc., Kitson House, Elmete Hall Elmete Lane, Roundhay University of Leeds, LS8 2LJ, U.K., 1995.

GRAVSOFT, A system for geodetic gravity field modelling, C. C. Tscherning, Department of Geophysics, Juliane Maries Vej 30, DK-2100 Copenhagen N. R. Forsberg and P. Knudsen, Kort og Matrikelstyrelsen, Rentemestervej-8, DK-2400 Copenhagen NV, 2005.

Heiskanen, W. A. and H. Moritz, Physical Geodesy, Freeman, San Francisco, 1967.

Helmut, L., A generalized form of Nettletons's density determination, Geophys. Prospect., 15, 247-258, 1965.

Huang, J., P. Vanicek, S. Pagiatakis, and W. Brink, Effect of topographical mass density variation on gravity and geoid in the Canadian Rocky Mountains, J. Geodyn., 74, 805-815, 2001.

Hunegnaw, A., The effect of lateral density variation on local geoid determination, Proc. IAG 2001 Sci. Assem., Budapest, Hungary, 2001.

Kiamehr, R., The impact of lateral density variation model in the determination of precise gravimetric geoid in mountainous areas: a case study of Iran, Geophys. J. Int., 167, 521-527, 2006.

Kuhn, M., GeoidBestimmung unter verwendung verschiedener dichtehypothesen. Deutsche Geodatische Kommission, in Dissertationen, Heft Nr. 520, edited by C. Reihe, Munchen, Gaermany, 2000a.

Kuhn, M., Density modelling for geoid determination. GGG2000, July 31August 4, 2000, Alberta, Canada, 2000b. 
Kuhtreiber, N., Precise geoid determination using a density variation model, Phys. Chem. Earth, 23(1), 59-63, 1998.

Lemoine, F. G., D. E. Smith, R. Smith, L. Kunz, N. K. Pavlis, S. M. Klosko, D. S. Chinn, M. H. Torrence, R. G. Williamson, C. M. Cox, K. E. Rachlin, Y. M. Wang, E. C. Pavlis, S. C. Kenyon, R. Salman, R. Trimmer, R. H. Rapp, and R. S. Nerem, The development of thr NASA, GSFC and NIMA joint geopotential model, in Gravzly, Geozd, and Marzne Geod., edited by Segawa, Fugimoto and Okubo, IAG Synzposza 117, Springer-Verlag, Berlin, 461-470, 1997.

Lisitzin, E., Sea level changes, Elsevier, Amsterdam, 1974.

Martinec, Z., Effect of lateral density variations of topographical masses in view of improving geoid model accuracy over Canada, Contract report for Geodetic Survey of Canada, Ottawa, Canada, 1993.

Martinec, Z., P. Vanicek, A. Mainville, and M. Veronneau, The effect of lake water on geoidal height, Manuscr. Geod., 20, 193-203, 1995.

Molodensky, M. S., V. F. Eremeev, and M. I. Yurkina, Methods for the study of the external gravitational field and figure of the Earth, Israeli Program for Scientific Translations, Jerusalem, 1962.

Nahavandchi, H., Two different methods of geoidal height determinations using a spherical harmonics representation of the geopotential, topographic corrections and height anomaly-geoidal height difference, $J$. Geod., 76, 345-352, 2002.

Nahavandchi, H. and L. E. Sjöberg, Terrain correction to power $H^{3}$ in gravimetric geoid determination, J. Geod., 72, 124-135, 1998.

Nafe, L. E. and C. L. Drake, Physical properties of marine sediments, in The sea Interscience, edited by Hill, 794-815, 1963.

Nettleton, L. L., Elementary gravity and magnetic for geologists and seismologists, SEG Monogr. Ser. l, 121, 1971.

Noor, E., J. Chen, L. Yulin, and J. Zhang, Report on data processing/adjustment regarding "A" \& "AB" order GPS networks of Pakistan June 15-24, 1997, Survey of Pakistan Rawalpindi, 1997.

Omang, O. C. D. and R. Forsberg, How to handle topography in practical geoid determination: three examples, J. Geod., 74, 458-466, 2000.

Pagiatakis, S. D. and C. Armenakis, Gravimetric geoid modelling with GIS, Int. Geoid Serv. Bull., 8, 105-112, 1999.

Rapp, R. H., Methods for the computation of geoid undulations from potential coe.cients, Bull. Geod., 101, 283-297, 1971.

Rapp, R. H., A FORTRAN Program for the computation of gravimetric quantities from high degree spherical harmonic expansions, Rep. 334, Dept. of Geodetic Science and Surveying, The Ohio State University, Columbus, Ohio, 1982.

Rapp, R. H., Global geoid determination, in Geoid and Its Geophysical Interpretations, edited by Vanicek and Christou, p. 57-76, CRC Press, Boca Raton. FL, 1994a.
Rapp, R. H., The use of potential coefficient models in computing geoid undulations. Intenational School for the determination and use of the geoid, Int. Geoid Serv., DIIAR-Politecnico di Milano, 71-99, 1994b.

Rapp, R. H., Use of potential coefficient models for geoid undulation determinations using a spherical harmonic representation of the height anomaly/geoid undulation difference, J. Geod., 71, 282-289, 1997.

Reigber, Ch., P. Schwintzer, R. Stubenvoll, R. Schmidt, F. Flechtner, U. Meyer, R. König, H. Neumayer, Ch. Förste, F. Barthelmes, S. Y. Zhu, G. Balmino, R. Biancale, J.-M. Lemoine, H. Meixner, and J. C. Raimondo, A High Resolution Global Gravity Field Model Combining CHAMP and GRACE Satellite Mission and Surface Data: EIGEN-CG01C, 2004.

Sadiq, M. and Z. Ahmad, A comparative study of the geoid-quasigeoid separation term $\mathrm{C}$ at two different locations with different topographic distributions, Newton's Bulletin, 3, 1-10, International Geoid Service www.iges.polimi.it, 2006.

Sadiq, M. and Z. Ahmad, On the selection of optimal global geopotential model for geoid modeling: a case study in Pakistan, Internal report\#11, Dept. of Earth Sciences QAU, Islamabad, 2007.

Sadiq, M., Z. Ahmad, and M. Ayub, Vertical gravity anomaly gradient effect on the geoid-quasigeoid separation and an optimal integration radius in planer approximation, Studia Geophys. Geod., 2008 (submitted). Sjöberg, L. E., On the error of spherical harmonic development of gravity at the surface of the Earth, Rep. 257, Department of Geodetic Science, The Ohio State University, Columbus, 1977.

Sjöberg, L. E., On the total terrain effects in geoid and quasigeoid determinations using Helmert second condensation method, Rep. 36, Division of Geodesy, Royal Institute of Technology, Stockholm, 1994.

Sjöberg, L. E., On the quasigeoid to geoid separation, Manuscr. Geod., 20, 182-192, 1995.

Thorarinsson, F. and S. G. Magnusson, Bouguer density determination by fractal analysis, Geophys., 55, 932-935, 1990.

Torge, W., Geodesy, 3rd ed., 2001.

Tziavos, I. N. and W. E. Featherstone, First results of using digital density data in gravimetric geoids computation in Australia, IAG Symposia, GGG2000, Springer Verlag, Berlin Heidelberg, 123, 335-340, 2000.

USGS, EROS, SRTM30 Digital Elevation Model DATA Center, SIOUX Fall, SD 57198-0001, http://srtm.usgs.gov/data/obtainingdata.html.

Vanicek, P., M. Naja, Z. Martinec, L. Harrie, and L. E. Sjöberg, Higher order reference field in the generalized Stokes-Helmert scheme for geoid computation, J. Geod., 70, 176-182, 1995.

M. Sadiq (e-mail: sdq_geo@yahoo.com),Z. Ahmad, and G. Akhter 